\title{
Dinámica geomorfológica de la costa de La Araucanía ${ }^{1}$
}

\author{
Fernando Peña-Cortés ${ }^{2}$, Carlos Limpert ${ }^{3}$, Elías Andrade ${ }^{4}$, \\ Enrique Hauenstein ${ }^{5}$, Jaime Tapia ${ }^{6}$, Carlos Bertrán ${ }^{7}$ y Luis Vargas-Chacoff ${ }^{8}$
}

\section{RESUMEN}

Se analizó la dinámica geomorfológica de la franja costera de La Araucanía mediante el método propuesto por Tricart (1985), Endlicher (1985) y la clasificación de Francke et al. (2004). En base a patrones morfológicos, morfométricos, morfogenéticos y de uso de suelo, las unidades geomorfológicas más representativas fueron el cordón montañoso en roca metamórfica y el cordón montañoso en roca metamórfica con intrusiones graníticas, ambas del Paleozoico, las plataformas en roca metamórfica y la llanura fluviomarina representada por humedales de alto valor ecológico. La erosión hídrica muestra un estado erosivo ligero-moderado en gran parte del área de estudio, asociado principalmente a factores antrópicos como la histórica disminución y cambio de cobertura vegetal, malas prácticas agrícolas y la casi nula aplicación de prácticas de conservación de suelos.

Palabras clave: Geomorfología costera, erosión hídrica, unidades geomorfológicas, morfometría, morfogénesis y paisaje cultural.

\begin{abstract}
This paper describes the geomorphology of the coast of La Araucania, using methods proposed by Tricart (1985) Endlicher (1985) and the classification methods of Francke et al. (2004). Based on morphological, morphometric, morphogenetic and land use patterns, the most representative geomorphic units were the mountain range of metamorphic rock, cord metamorphic rock mountain with granite intrusions, both Paleozoic, the metamorphic rock platform and the fluvial-marine plain represented by wetlands of high ecological value. Water erosion was low to moderate in much of the study area and is mainly associated with human factors, such as the historic reduction and change in vegetation cover, poor agricultural practices and almost no application of soil conservation practices.
\end{abstract}

Key words: Coastal geomorphology, hydric erosion, geomorphological units, morphometric, morphogenesis and cultural landscape.

\footnotetext{
1 Se agradece al proyecto FONDECYT 1110798 por el financiamiento de esta investigación y a Jimmy Pincheira y Marco Estrada por su contribución en la revisión y edición del manuscrito. Artículo recibido el 30 de septiembre de 2013, aceptado el 28 de noviembre de 2013 y corregido el 12 de marzo de 2014.

2 Escuela de Ciencias Ambientales, Universidad Católica de Temuco (Chile). E-mail: fpena@uct.cl

3 Escuela de Ciencias Ambientales, Universidad Católica de Temuco (Chile).E-mail: climpert@uct.cl
}

4 Escuela de Ciencias Ambientales, Universidad Católica de Temuco (Chile). E-mail: eandrade@uct.cl

5 Escuela de Ciencias Ambientales, Universidad Católica de Temuco (Chile).E-mail: ehauen@uct.cl

6 Instituto de Química de Recursos Naturales, Universidad de Talca (Chile). E-mail: jtapia@utalca.cl

7 Instituto de Ciencias Marinas y Limnológicas, Universidad Austral de Chile (Chile)

E-mail: cbertran@uach.cl

8 Instituto de Ciencias Marinas y Limnológicas, Universidad Austral de Chile (Chile).

E-mail: luis.vargas@uach.cl 
El sur de Chile ha sufrido cambios en el espacio geográfico desde la llegada de los españoles, quienes introdujeron la agroganadería en detrimento del bosque nativo u otros espacios naturales provocando un importante proceso de alteración del paisaje ecológico (Endlicher, 1988; Bengoa, 1991; Donoso \& Lara, 1997; Torrejón \& Cisternas, 2002). Con el tiempo estos cambios se han incrementado, inclusive con el respaldo del Estado, a través de la puesta en marcha de instrumentos de fomento al sector silvoagropecuario (Peña-Cortés et al., 2009).

Esta situación, sumado a la introducción de especies exóticas y los cambios en los ciclos biogeoquímicos, ha derivado en alteraciones de la dinámica geomorfológica en las costas del sur de Chile, lo que ha traído como consecuencia que los procesos geomorfológicos, como la erosión del suelo, la sedimentación y las inundaciones sean uno de los problemas ambientales más graves y recurrentes (Vitousek et al., 1997; Meybeck \& Vorosmarty, 2004; Peña-Cortés et al., 2010).

El inadecuado uso de los recursos naturales y el efecto de los procesos físicogeográficos y socioeconómicos, alteran la organización de los diferentes elementos que conforman el medio ambiente y que a su vez caracterizan el espacio geográfico. En este contexto, las investigaciones sobre los cambios actuales de la cobertura terrestre, deben estar sustentados por estudios geográficos adecuados que permitan brindar la información básica necesaria acerca de los efectos que tienen las diferentes actividades antrópicas sobre el relieve (Luis, 2004).

En Chile, uno de los territorios más deprimidos ambientalmente se localiza en la Región de La Araucanía, caracterizado por sus altos niveles de pobreza, indigencia, migración poblacional y un grave desequilibrio ambiental (Böergel, 1986; Peña-Cortés et al., 2005, 2006a, 2006b y 2009). La Cordillera de la Costa de la Región de La Araucanía registra según IGM (1986) un acusado descenso del continente. Este sector se caracteriza por el desplazamiento hacia el oeste de la Depresión Central, la cual se confunde con el litoral por efecto de un antiguo relieve montañoso costero, el que actualmente está reducido a suaves colinas producto de la erosión y su exposición al mar. Están estructurados en un conjunto litológico homogéneo de esquistos y granitos de edad Paleozoica (Mardones, 2005), cordón que desaparece entre los ríos Pellahuén e Imperial. Desde este sector hacia el sur, se extiende longitudinalmente la planicie litoral por aproximadamente $75 \mathrm{~km}$ y con un ancho de $25 \mathrm{~km}$, siendo modelada por la acción del mar y movimientos tectónicos, la que está compuesta principalmente por depósitos tanto marinos, como fluviales, ubicándose entre los ríos Moncul y Queule. En el sector oeste, los relieves están estructurados principalmente por la serie oriental del Basamento Metamórfico.

Diversos autores han descrito la geomorfología costera regional, como el IGM (1986) quien hace una descripción geomorfológica, de sus recursos y de sus riesgos naturales, entre otros aspectos. Por otro lado, Mardones (2005) en su estudio "Marco geomorfológicoclimático de la Cordillera de la Costa del centro-sur de Chile" realiza una descripción de las regiones morfoestructurales de la Cordillera de la Costa, su formación, composición y procesos morfogenéticos. Por su parte, PeñaCortés et al. (2008), evaluaron la dinámica de los campos dunarios del borde costero de La Araucanía, usando una clasificación morfológica y grado de estabilización. Recientemente Peña-Cortés et al. (2011a, 2011b), en el mismo sector descrito anteriormente, analizaron la distribución geográfica de los bosques pantanosos, para ello realizaron un levantamiento de información, donde se identificaron unidades geomorfológicas, capacidad de uso del suelo, clases de drenaje, entre otros. Por otro lado, Peña-Cortés et al. (2010) analizaron el cambio de uso de suelo producido en los geosistemas de una cuenca costera entre los años 1994 y 2004, y para ello, realizaron una caracterización geomorfológica de la cuenca identificando unidades y procesos geomorfológicos.

Por otro lado, autores como Elizalde (1970), Endlicher (1988), Oyarzún (1993), Iroumé et al. (1994), Peña-Cortés (1999), Honorato et al. (2001) han evaluado la erosión hídrica en el relieve cordillerano costero, principalmente en la Región del Biobío. En el caso de la Región de La Araucanía, los pocos estudios referentes a erosión hídrica que se han realizado, se enfocan en sectores empla- 
zados sobre la vertiente oriental de la cordillera de Nahuelbuta (IREN-CORFO, 1979; Iroumé et al., 1994; Honorato et al., 2001).

En este contexto, el presente trabajo pretende hacer una detallada descripción a escala 1:20.000 de la geomorfología costera de la Región de La Araucanía, mediante una metodología de trabajo de campo y gabinete. En forma complementaria se cuantifica la presencia de procesos morfogenéticos de erosión hídrica como es el caso de la erosión lineal y laminar, lo que servirá como base para una mejor comprensión de la dinámica geomorfológica y los problemas ambientales que afectan a la zona litoral costera de La Araucanía con el fin de propiciar la conservación y la gestión territorial de estos espacios (Iroumé et al., 1994; PeñaCortés et al., 2006a, 2008, 2009 y 2011 b).

\section{Materiales y métodos}

El área de estudio se ubica en la zona costera de la provincia de Cautín, Región de La Araucanía, entre los $38^{\circ} 47^{\prime}$ y $39^{\circ} 41^{\prime}$ de latitud sur y los $73^{\circ} 47^{\prime}$ y $73^{\circ} 15^{\prime}$ de longitud oeste, con una extensión de 108 km aproximadamente desde el río Danquil por el norte hasta el río Queule por el sur, abarcando las comunas de Carahue, Nueva Imperial, Teodoro Schmidt, Saavedra y Toltén (Figura No 1).

Morfológicamente, el área se caracteriza por ser una zona de contacto entre la CordiIlera de la Costa y la Ilanura de subsidencia, la cual ha sido modelada por las características del clima, suelo, vegetación, acción de agentes erosivos, sistemas fluviales y actividades antrópicas, lo que ha generado una gran diversidad de paisajes en la costa de La Araucanía (Mardones, 2005). Los relieves de erosión están compuestos por roca de origen metamórfico de edad Paleozoica, presentan erosión moderada y una fuerte tendencia a uso forestal (Peña-Cortés, 1995, 2008, 2011a). Las principales cotas tienen forma de cordones desgastados, con pendientes convexas donde se evidencia una intensa disección de los cordones, que sumado a la profundidad de los valles confirman la antigüedad del proceso erosivo (Mardones, 2005).

El clima juega un papel fundamental en la morfogénesis del área de estudio. El marcado contraste entre el verano seco y con altas temperaturas y el invierno caracterizado por fuertes y persistentes Iluvias (1.500 a 2.000 $\mathrm{mm} / \mathrm{año)}$ concentradas entre los meses de mayo-octubre estimulan los procesos de erosión hídrica (Endlicher, 1988; Peña-Cortés et al., 2006; Inzunza, 2009). Según IGM (1986) y Luebert y Pliscoff (2005), en la provincia de Cautín se observa un clima templado típico con influencia oceánica, donde la estación seca ya no existe y se reduce a uno o dos meses en el año, distribuyéndose tanto en la costa, como en el interior de la Región de La Araucanía y en las partes bajas de la vertiente oriental de la Región de Los Lagos entre los 0-400 m. Es importante destacar la diferencia de precipitaciones entre el sector norte (provincia de Malleco) y el área de estudio, para dejar en claro la relevancia de esta variable y su influencia en los procesos de morfogénesis.

\section{Información base y procesamiento cartográfico}

Mediante la fotointerpretación de fotografías aéreas a color escala 1:20.000 de los vuelos FONDECYT 1030861 año 2004; 1080317 año 2009 y 1110798 año 2011. Posteriormente, esta información fue corroborada en terreno, procesada y editada digitalmente con el programa ArcGis versión 9.3 con sus extensiones Spatial Analyst y XTools Pro, mediante las cuales se obtuvieron datos morfométricos (pendiente y exposición) y de superficie por unidad geomorfológica respectivamente. Las cotas de altitud se obtuvieron por medio de las curvas de nivel de las cartas topográficas del Instituto Geográfico Militar (IGM) escala 1:25.000 y escala 1:50.000 año 1983 y año 1969 respectivamente. La información correspondiente a series, profundidad, composición y drenaje del suelo, fueron obtenidas a través del estudio agroecológico de CIREN (2002).

\section{Análisis de la geomorfología}

El análisis de la geomorfología se basó en la metodología propuesta por Tricart (1985), utilizada por diversos autores como Aparecida \& Lupinacci (2007); Llona et al. (2007), Suvires \& Luna (2008), y Modenesi-Gauttieri et al. (2011). Se clasificó cada unidad según 
Figura $\mathrm{N}^{\circ} 1$

Área de estudio costa de La Araucanía. Chile

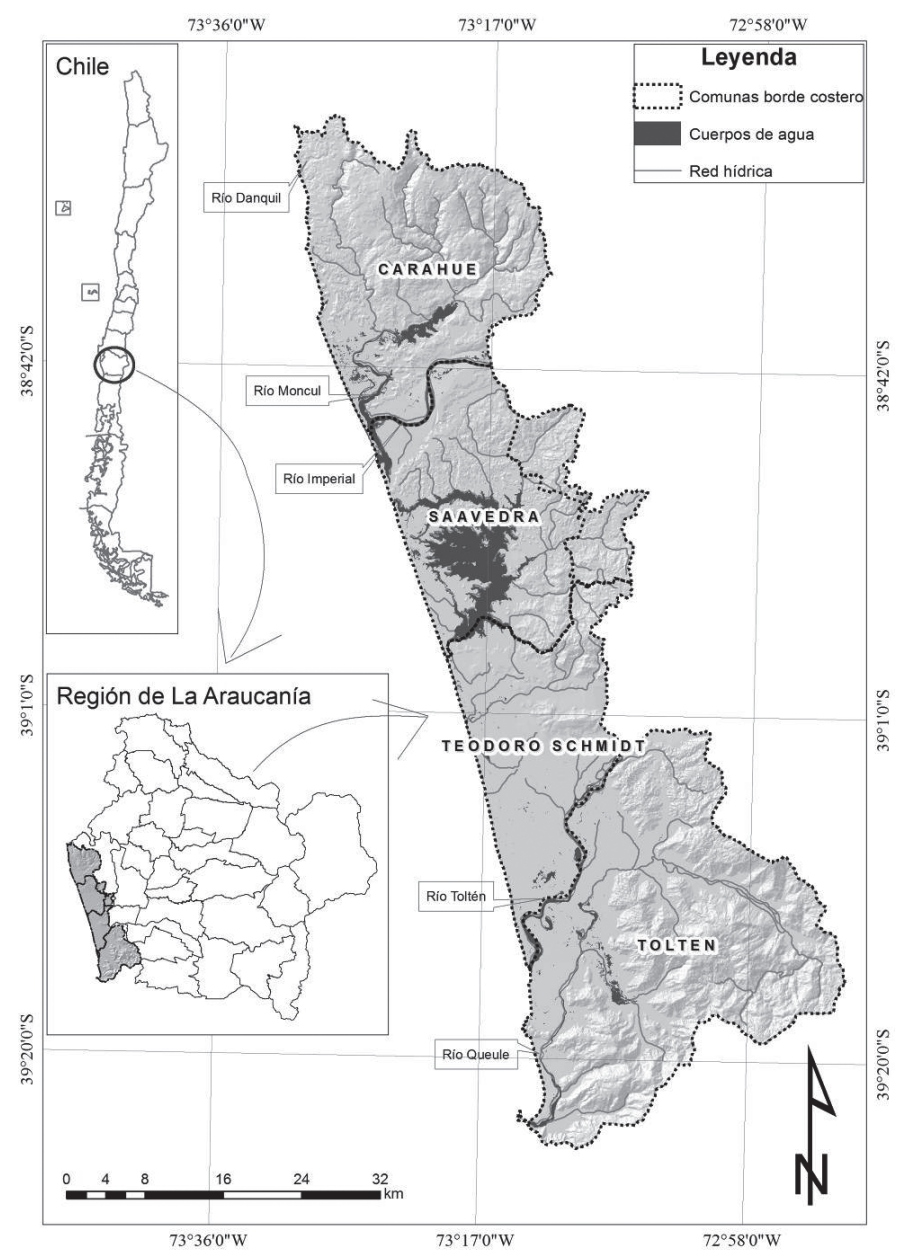

Fuente: Elaboración propia en base a FONDECYT 1030861, 1080317 y 1110798.

criterios genéticos, morfológicos, morfométricos y de uso de suelo (Peña-Cortés, 1999). Las unidades geomorfológicas identificadas se ordenaron en relieves de erosión, relieves de acumulación y/o modelado litoral (formación de dunas litorales) según su jerarquía (cordones montañosos, plataformas, terrazas, llanuras, cordones litorales y dunas) (PeñaCortés \& Mardones, 1999).

La edición de las coberturas y las cartas temáticas se realizaron mediante la utilización del software ArcGIS 9.3. Cabe mencionar que, por logística y para facilitar el ma- nejo y análisis de la información, el área de estudio se separó en tres unidades de norte a sur por los principales sistemas fluviales de la costa de La Araucanía: río Danquil, río Imperial, río Toltén y río Queule.

\section{Evaluación de la erosión hídrica}

Para la identificación y clasificación de los procesos morfogenéticos se utilizó el método cualitativo propuesto por Endlicher (1985) y modificado por Peña-Cortés (1999), donde según lo interpretado en las fotografías aéreas y antecedentes cualitativos de la erosión, se 
clasificó de primer a tercer orden de acuerdo al grado de formación y profundización de los surcos (Anton, 2006; FAO, 2006). La erosión de primer orden corresponde a erosión lineal incipiente. La de segundo orden consiste en la formación de la cabecera de la cárcava y la de tercer orden representa la cárcava completa (corredor y cabecera) (ver Cuadro $\mathrm{N}^{\circ} 1$ ). La densidad de estas se obtuvo de acuerdo a una cuadrícula definida por paralelos y meridianos equidistantes de $1 \mathrm{~km}$, por lo que se evaluaron superficies de $1 \mathrm{~km}^{2}$.

Respecto a la erosión hídrica laminar, se definió en base a antecedentes cualitativos, en niveles de moderada a severa, de acuerdo al grado de decoloración del suelo y considerando su área en relación al total del relieve de erosión y en las unidades geomorfológicas en las cuales se presentó. La de tipo moderada corresponde a la decoloración parcial y la de tipo severa corresponde a la decoloración total de la superficie del suelo (Cuadro $N^{\circ} 1$ ).

Con esta información se determinó el estado erosivo de cada unidad de observación, basada en la clasificación propuesta por Francke et al. (2004) (ver Cuadro N²).

Cuadro $\mathrm{N}^{\circ} 1$

Clasificación de los procesos geomorfológicos

\begin{tabular}{|l|l|}
\hline Erosión en Manto & \multicolumn{1}{c|}{ Erosión Lineal } \\
\hline $\begin{array}{l}\text { Moderada (decoloración parcial del } \\
\text { suelo). }\end{array}$ & $\begin{array}{l}\text { Primer Orden (canalículos y regueros). } \\
\text { Segundo Orden (zanjas y cárcavas, con vegetación, cabecera } \\
\text { activa). } \\
\text { Tercer Orden (cárcavas con ausencia de vegetación). }\end{array}$ \\
\hline
\end{tabular}

Fuente: Elaboración propia basada en Endlicher (1985) y modificado por Peña-Cortés (1999).

Cuadro $\mathrm{N}^{\circ} 2$

Categorías de erosión y sus respectivos indicadores

\begin{tabular}{|c|c|}
\hline Categoría & Indicadores \\
\hline $\begin{array}{l}\text { 1. Erosión moderada se } \\
\text { puede manifestar en tipos } \\
\text { de erosión laminar o de } \\
\text { manto de nivel medio, o } \\
\text { en surcos o de canalículos. }\end{array}$ & $\begin{array}{l}\text { Presencia del subsuelo en al menos el } 15 \% \text { de la superficie. } \\
\text { Presencia de pedestales y pavimentos de erosión en al menos el } 15 \% \text { de la } \\
\text { superficie. } \\
\text { Pérdida de suelo original entre el } 20 \% \text { y el } 60 \% \text {. } \\
\text { Presencia de surcos o canalículos, de profundidad menor a } 0,5 \text { metro. } \\
\text { Pérdida de más de un } 30 \% \text { del horizonte A (orgánico-mineral). }\end{array}$ \\
\hline $\begin{array}{l}\text { 2. Erosión severa se puede } \\
\text { manifestar en tipos de ero- } \\
\text { sión laminar o de manto } \\
\text { intensiva, o de zanjas o } \\
\text { cárcavas. }\end{array}$ & $\begin{array}{l}\text { Presencia del subsuelo en un área entre } 15 \% \text { y } 60 \% \text { de la superficie. } \\
\text { Presencia de pedestales y pavimentos de erosión entre el } 15 \% \text { y } 60 \% \text { de la } \\
\text { superficie. } \\
\text { Pérdida del suelo original entre el } 60 \% \text { y } 80 \% \text {. } \\
\text { Presencia de zanjas o cárcavas de profundidad de } 0,5 \text { a } 1 \text { metro, encontrán- } \\
\text { dose a un distanciamiento medio de } 10 \text { a } 20 \text { metros. } \\
\text { Pérdida de hasta un } 30 \% \text { del horizonte B (mineral). }\end{array}$ \\
\hline $\begin{array}{l}\text { 3. Erosión muy severa se } \\
\text { puede manifestar en tipos } \\
\text { de erosión laminar o de } \\
\text { manto muy acelerados, o } \\
\text { de cárcavas. }\end{array}$ & $\begin{array}{l}\text { Se presenta a la vista el subsuelo y se encuentra visible el material de origen } \\
\text { del suelo, en más del } 60 \% \text { de la superficie. } \\
\text { Presencia de pedestales y pavimentos de erosión, en más del } 60 \% \text { de la su- } \\
\text { perficie. } \\
\text { Pérdida del suelo original entre el } 60 \% \text { y } 80 \% \text {. } \\
\text { Presencia de zanjas o cárcavas de profundidad de } 0,5 \text { a } 1 \text { metro, encontrán- } \\
\text { dose a un distanciamiento medio de } 10 \text { a } 20 \text { metros. } \\
\text { Pérdida de hasta un } 30 \% \text { del horizonte B (mineral). }\end{array}$ \\
\hline
\end{tabular}

Fuente: Francke et al. (2004). 


\section{Geomorfología de la costa de La Araucanía}

\section{Río Danquil - río Imperial}

Al sur del río Danquil el relieve se presenta con un marcado dominio de los relieves de erosión conformados por cordones montañosos y plataformas en roca metamórfica de edad Paleozoica (Mardones, 2005). El cordón montañoso de esta zona corresponde a la parte final de la cordillera de Nahuelbuta por el sur y debido a su composición se presenta muy reducido y seccionado por los cursos de agua donde la depresión intramontañosa del río Puyanhue lo divide en dos ejes orográficos con orientación norte-sur.

El primer eje se ubica en el sector noroeste (Figura $N^{\circ} 2$ ), desde el sector de Yupehue hasta Punta Cautén con una longitud de 13 $\mathrm{km}$ aproximadamente, posee alturas que no superan los 300 msnm y pendientes máximas de $30^{\circ}$. El margen litoral del sector se caracteriza por presentar una intensa morfogénesis, lo que deja en evidencia el actual proceso de desgaste al que está sometido dada su ubicación y exposición a la costa y al uso principalmente agrícola-forestal. La acción antrópica ha sido decisiva en la degradación de estos suelos por la utilización del fuego en la agricultura extensiva y de secano desde los tiempos de la Colonia (Bengoa, 1991; Peña-Cortés, 1999). Por otro lado, existe un importante proceso de acreción marina sobre la costa, condición que se refleja en el alto número de cornisas que se encuentran sobre los escarpes de ladera del cordón montañoso en la costa, desde el sector de Caicoi al norte. En el margen occidental, se puede evidenciar la presencia de un antiguo paleocauce (desde Punta Cautén hasta el norte de Champulli) y su salida que presenta hacia la costa de la cuenca podría estar relacionada con una antigua zona mareal que por un tipo de falla de cabalgamiento quedó a una mayor exposición.

Figura $\mathrm{N}^{\circ} 2$

Geomorfología. Río Danquil - Río Imperial

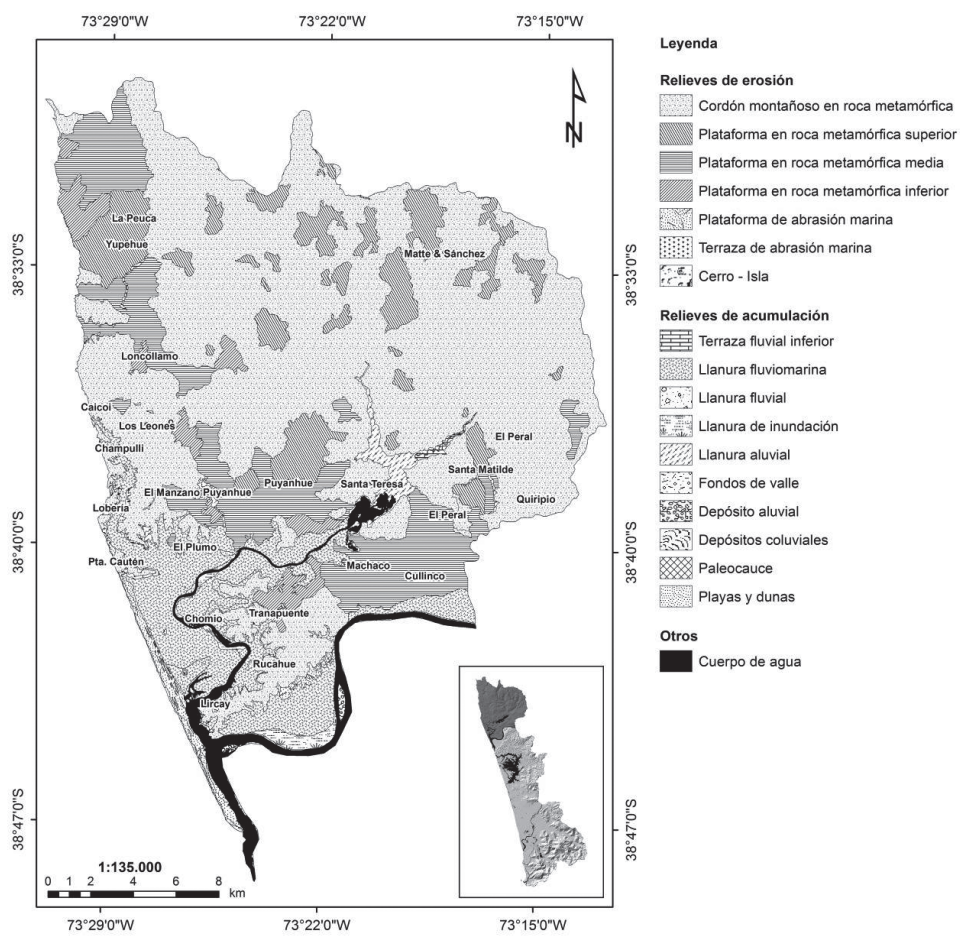

Fuente: Elaboración propia en base a proyectos FONDECYT 1030861, 1080317, 1110798. 
El segundo eje se presenta como un bloque macizo y elevado. Se ubica por el lado este del estero Chanco hasta el río Puyanhue (Figura $\mathrm{N}^{\circ} 2$ ). Posee alturas que pueden alcanzar los $860 \mathrm{msnm}$ y pendientes máximas de $80^{\circ}$ en el sector oriental. La gran superficie que abarca la serie de suelo Asociación Nahuelbuta, da cuenta de los altos sectores que posee la cordillera de Nahuelbuta en este tramo, de topografía escarpada, con pendientes promedio de $13^{\circ}$ a $23^{\circ}$, de clima desfavorable y con riesgo inminente de erosión (CIREN, 2002).

Estos suelos poseen un alto contenido de arcillas en el horizonte B (perfil del suelo), lo que hace que en periodos secos se forme una capa gruesa e impermeable, y en estaciones lluviosas si están desprotegidos de vegetación, generan una densificación de los horizontes inferiores del suelo. Esto se traduce en una baja capacidad de campo que finalmente conduce a una elevada escorrentía superficial, facilitando la formación de surcos en las laderas por arrastre de material (Endlicher, 1988).

Las plataformas en roca metamórfica se presentan como unidades onduladas, diferenciadas en tres tipos según su altitud. La primera, corresponde a la plataforma inferior, es la de menor altura (<200 msnm) con orientación noroeste-sureste y comprende los sectores de La Peuca, Colonia Loncollamo, Los Leones, El Manzano, Cautén, El Plumo, en la desembocadura del río Puyanhue y Colonia Tranapuente por el sur. En segundo lugar están las plataformas de nivel medio, con alturas que no superan los 400 msnm y pendientes máximas de $20^{\circ}$. Poseen la misma orientación noroeste-sureste que las plataformas inferiores ya que se ubican en forma intermitente. Estas, se emplazan en sectores como Colonia Loncollamo, Agua Blanca, Chomio, Machaco y Cullinco.

En tercer lugar, con alturas que no superan los 900 msnm y en su mayoría emplazadas sobre el cordón montañoso están las plataformas de nivel superior, abarcan sectores del estero Las Ñochas, Cabrero, CoIonia Matte \& Sánchez, Santa Teresa y Santa Matilde (Figura No 2). Presenta procesos de erosión lineal principalmente, pero con menor agresividad que en plataformas de niveles inferiores. Las plataformas de nivel medio e inferior, se caracterizan por presentar una activa e intensa morfogénesis, lo que se refleja en los diferentes tipos y niveles de erosión. Predominan los suelos de las series Araucano y Puerto Saavedra, Ios que se caracterizan por tener buen drenaje y pendientes que oscilan entre $5^{\circ}$ y $13^{\circ}$, posee baja capacidad de retención de agua y serias limitaciones agrícolas, por lo que son suelos destinados solamente a uso forestal y pastizales, lo que su vez, explica su nivel de degradación ( $\mathrm{Cl}$ REN, 2002).

Con respecto a los relieves de acumulación, la unidad más representativa es la llanura fluviomarina, la cual comprende un amplio sistema de humedales con alto valor ambiental. Esta zona presenta una morfogénesis asociada a la acumulación de sedimento, arrastrado y depositado por los cursos de agua y el mar. Otro aspecto importante con respecto a su morfogénesis, es lo que señala Cisternas et al. (2000), que a raíz del tsunami provocado por el terremoto de Valdivia del año 1960, los terrenos descendieron considerablemente (entre 1 a $4 \mathrm{~m}$ ) formando extensos humedales en las zonas de desembocadura de los ríos Imperial y Toltén, por lo que el origen de este ecosistema podría tener su explicación en este fenómeno natural (Cisternas et al., 2005). Estas unidades se caracterizan por presentar severos procesos de anegamiento pobladas por vegetación palustre, tales como juncales y totorales, además de tener una gran diversidad de avifauna (Peña-Cortés et al., 2006a; Hauenstein et al., 2008). Es una planicie litoral de abrasión y sedimentación fluviomarina, que por su cercanía al litoral tiene una gran influencia en el sector. Abarca los sectores de Champulli, Lobería, Cautén, Rucahue hasta Lircay por el occidente y desde la laguna Trovolhue hasta Chomio por el oriente. Sobre estas Ilanuras se emplazan los humedales de Moncul, los que están asociados especialmente a las riberas de los principales cursos y cuerpos de agua del sector como son la laguna Trovolhue y el río Moncul, también existen zonas de humedales asociadas a cursos más pequeños como el estero San Juan de Trovolhue, estero El Peral y río Puyanhue. Por otro lado, con respecto al modelado litoral del sector se observan unidades de estrán, cordones litorales y dunas borderas principalmente. Cabe destacar que estos relieves se encuentran seriamente alte- 
rados debido a la acción del viento, del mar y principalmente del hombre. Esto se evidencia por la formación de pequeñas lagunas en la línea litoral, causado principalmente por la acción de vehículos motorizados $4 \times 4$, que sumado a la extracción de áridos, modifican su morfología afectando no solo el paisaje, sino que sus funciones ecológicas tales como ser hábitat para una amplia biodiversidad y ser barrera natural de protección contra las olas (Paskoff et al., 2000).

\section{Río Imperial - río Toltén}

Al sur del río Moncul se ubica el tramo litoral Ilamado "Planicie de Carahue" donde la Depresión Central se desplaza hacia el oeste confundiéndose prácticamente con el litoral. Posee una longitud de $57 \mathrm{~km}$, un ancho máximo de $24,5 \mathrm{~km}$ a la altura del sector de Isla Huapi y la altitud máxima la alcanza en el cerro Alto Molco con 412 msnm (Figura $\left.\mathrm{N}^{\circ} 3\right)$.

Figura $\mathrm{N}^{\circ} 3$

Geomorfología. Río Imperial - río Toltén.

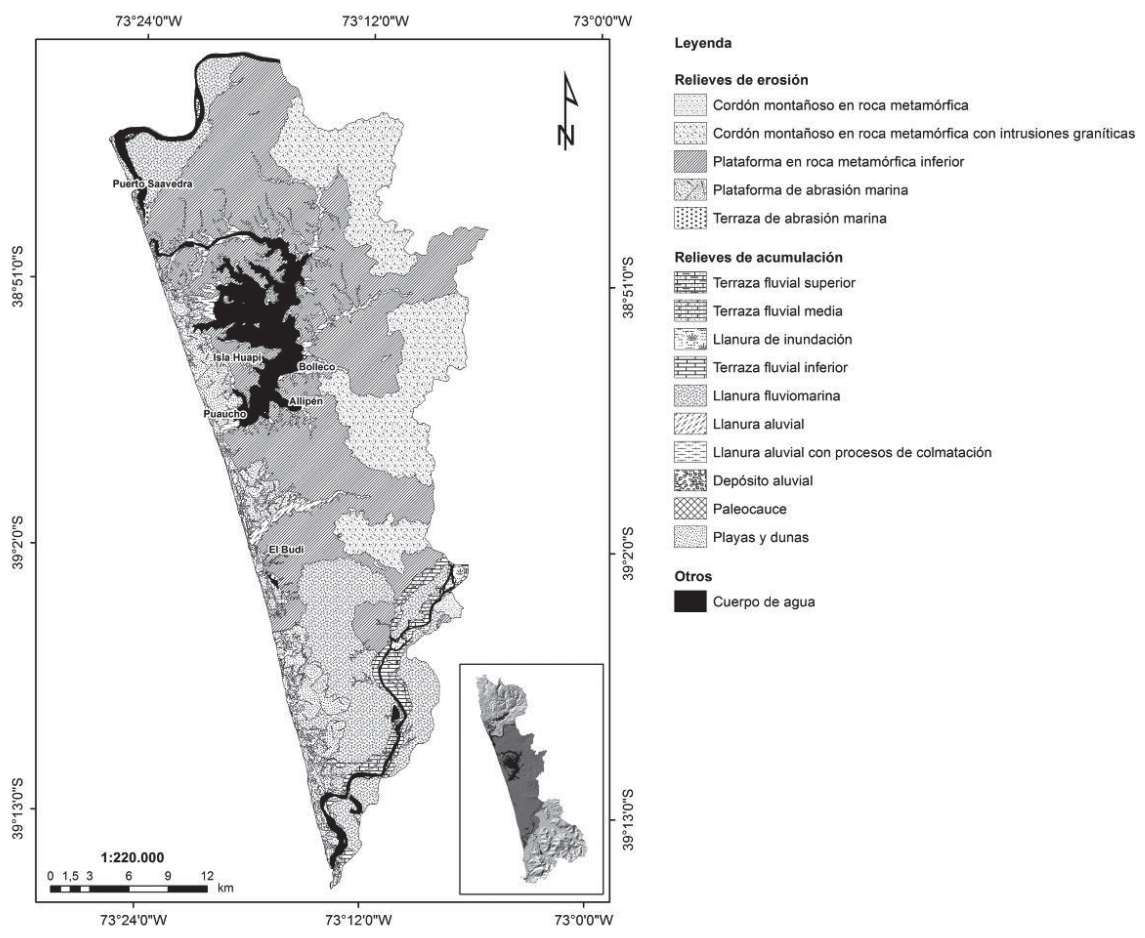

Fuente: Elaboración propia en base a proyectos FONDECYT 1030861, 1080317, 1110798.

En el sector costero, sobre una planicie litoral de aproximadamente $15 \mathrm{~km}$ de ancho, se emplaza el lago Budi, donde Mardones (2005) lo define como un sistema lacustre originado por obstrucción eólica y que funciona como laguna costera, en cuyo interior, las mareas tienen influencia en sus propiedades físicas, químicas y dinámicas (Figura $\mathrm{N}^{\circ} 4$ ).
$\mathrm{Al}$ igual que el sector que comprende los ríos Danquil - Imperial, este tramo se caracteriza por un predominio de los relieves de erosión, constituido en su mayoría por plataformas en roca metamórfica (Figura $N^{\circ} 4$ ). Según Oyarzún (1993), tal característica implica un alto riesgo que se generen procesos de erosión hídrica por la morfología y sus altas 
pendientes. En este sector, el cordón montañoso se divide en tres unidades. La primera se ubica en el margen noreste del área (Figura $N^{\circ} 3$ ), posee una disposición en forma de flecha la que se orienta de noreste a suroeste, lo que da origen a cuencas de recepción de aguas Iluvia y a los dos principales afluentes del estero Temo, donde su altitud alcanza los 275 msnm. La segunda unidad de cordón se ubica en el límite oriental del área, su orientación es de noreste a suroeste y presenta altitudes que fluctúan entre los 100 a 400 msnm, dando origen a una red hídrica que drena al estero Comué. Los cursos de agua que drenan la cara occidental de este cordón, dan origen a tres esteros tributarios del lago Budi: Bolleco, Maitenco y Allipén. Finalmente, el tercer fragmento de cordón se ubica en el margen sur del área, con orientación este-oeste y su altitud varía entre los 50 a los 275 msnm y da origen a una red hídrica de segundo orden que drena al estero Chelle.

Morfogenéticamente, la unidad está asociada a procesos de erosión hídrica diferen- cial, los cuales se potencian con la baja cobertura vegetal producto de la deforestación y al uso inapropiado del suelo (agrícola, forestal y ganadero) (Peña-Cortés et al., 2009). Estos suelos, de igual manera que el sector norte presentan en su mayoría la serie Nahuelbuta, los cuales poseen una alta erodabilidad (CIREN, 2002).

Las plataformas presentes en el sector, conservan la misma forma ondulada que en el sector norte (Figura $N^{\circ} 4$ ). Están estructuradas en roca metamórfica y las series de suelo más representativas son: Puerto Saavedra, Nahuelbuta y Suelos Recientes. Conforme a su altitud se diferenciaron dos tipos de plataformas: inferior y superior. La plataforma de nivel inferior, en relación a su altitud no supera los 50 msnm y se extiende desde el sector meridional de Romopulli hasta el estero Chelle y longitudinalmente abarca desde la desembocadura del estero Bolleco hasta la ribera occidental del lago Budi. Por otro lado, la plataforma de nivel superior, presenta una mayor altura que varía desde los 25 hasta los 125 msnm, eviden-

Figura $\mathrm{N}^{\circ} 4$

Relieve costero en la cuenca del Budi

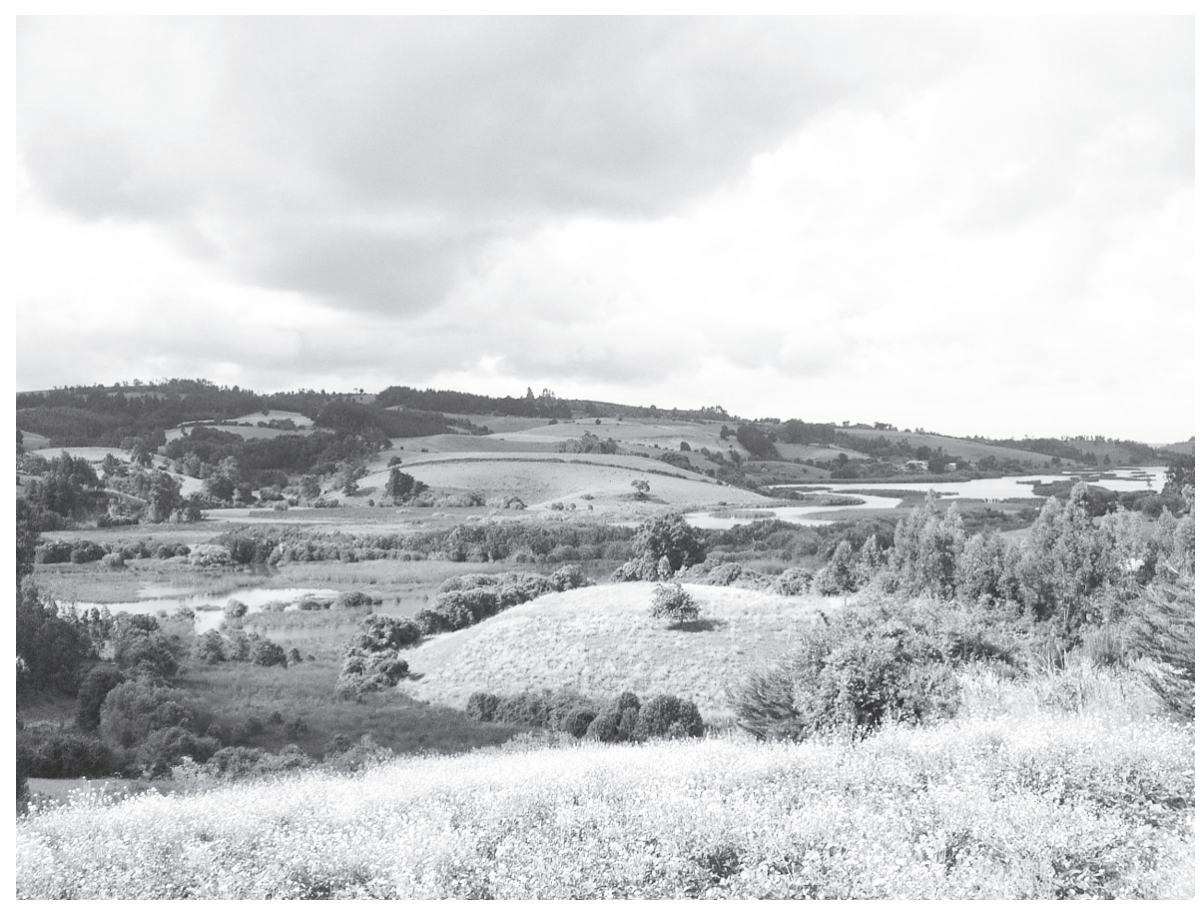

Fuente: Archivo personal de los autores. 
ciándose procesos de erosión laminar y lineal. Abarca la ribera oriental del lago Budi entre el sector septentrional de Romopulli, hasta la desembocadura del estero Bolleco en el sur.

Entre los procesos geomorfológicos más importantes se destacan la solifluxión en terraceta, erosión laminar, erosión lineal, derrumbes y deslizamientos. Esto se debe a la reducción y cambio de cobertura vegetal producida por el hombre durante las últimas décadas, por ejemplo al uso intensivo del suelo, la alta división predial y el uso de técnicas inadecuadas de cultivo (Endlicher, 1988; Oyarzún, 1993; Iroumé et al., 1994; Peña-Cortés \& Mardones, 1999; Mardones, 2005; Peña-Cortés et al., 2009). Sin embargo, la morfogénesis en la plataforma inferior es mucho menor, ya que solo se observan procesos de erosión laminar, y los de erosión lineal ocurren de forma esporádica.

Con respecto al relieve de acumulación, se destacan las unidades de Ilanura aluvial y llanura fluviomarina (Figura $N^{\circ} 3$ ). La llanura aluvial, corresponde a depresiones del terreno con procesos de anegamiento estacional, donde su morfogénesis está asociada a la acumulación de material transportado y depositado por cursos de agua. Las grandes extensiones que abarca esta unidad, están asociadas a los esteros Temo, Comué, Bolleco, Maitenco, Allipén, Chelle, río Budi y sus tributarios. Se caracterizan por tener suelos recientes, los cuales tienen limitaciones de drenaje y procesos de anegamiento e inundación y se pueden observar en alturas que no superan los 200 msnm. La Ilanura fluviomarina con anegamiento estacional se ubica en la parte norte del sector, en la ribera sur del río Imperial. Corresponden a sectores de vegas, cuyo nivel freático es relativamente alto, donde los depósitos de estos suelos son pesados, arcillosos y de mal drenaje.

Por otro lado, la llanura fluviomarina con procesos de anegamiento permanente, se ubica dividida en dos sectores en la ribera occidental del lago Budi (Puaucho y en la ribera del estero Carilón) y su origen se asocia a la influencia marina y del lago en conjunto, donde también se destaca el maremoto del año 1960. Corresponde a un área de humedales de la cuenca del lago Budi. Actualmente, se observa una acumulación excesiva de material en áreas de humedales y riberas del lago Budi, teniendo como efecto la subida en el nivel de agua de los ríos, aumentando año tras año las superficies de suelos inundados, lo que se advierte mejor con las Iluvias de invierno (Morgan, 1997; Hauenstein et al., 2008).

Por otra parte, el modelado litoral que se presenta en este sector corresponde principalmente a modelados dunarios activos, estrán y banco litoral (o barra litoral). Según el tamaño de su superficie, el modelado dunario comprende dunas paralelas, dunas borderas, depresiones húmedas y dunas transversales. Su diversidad de formas se explica por una alimentación de arena a partir de la playa, y la presencia de fuertes vientos sin ser obtaculizados (Peña-Cortés et al., 2008). Por otro lado, el estrán se observa a través de toda la línea litoral del área, constituido por arenas y gravas, se presenta disectado por porciones de acantilados vivos sobre plataformas litorales. Posee una extensión aproximada de $24,8 \mathrm{~km}$ y sus sedimentos corresponden a arenas de color negro de origen andesítico y basáltico. Por último, el banco litoral se ubica paralelamente frente a la ciudad de Puerto Saavedra. El área comprendida entre este y la ciudad da origen actualmente a una zona estuarina, de gran importancia para la actividad pesquera y para el cultivo de algas (Gracilaria chilensis) y choritos (Choromytilus chorus) (Guerrero, 2003). Su morfogénesis se debe al aporte de sedimentos por parte de los sistemas fluviales Imperial y Moncul.

\section{Río Toltén - río Queule}

Al igual que en los sectores anteriormente descritos, en este sector, los relieves de erosión abarcan una mayor superficie en comparación con los relieves de acumulación. Dentro de las unidades geomorfológicas más importantes destacan, el cordón montañoso en roca metamórfica del Paleozoico, la Ilanura fluviomarina y la llanura aluvial (Figura $N^{\circ}$ 5). Desde el valle del río Toltén, los cordones esquistosos y fragmentados de Mahuidanche se elevan sobre las Ilanuras de Gorbea avanzando hacia el este para encontrarse con la cordillera andina. Según Mardones (2005) la formación del cordón costero data del Plioceno superior y Cuaternario antiguo, lo que explicaría su alto nivel de degradación. 
Figura $\mathrm{N}^{\circ} 5$

Relieve costero en el sector de Boroa

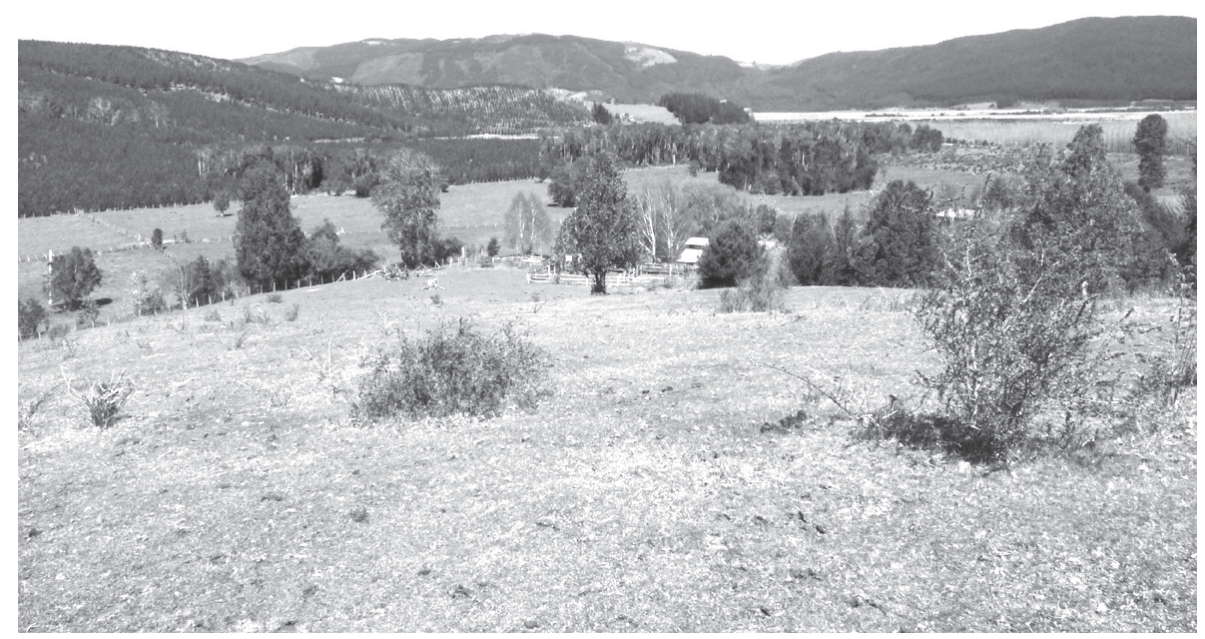

Fuente: Archivo personal de los autores.

Específicamente, en la vertiente occidental de Mahuidanche, desde el estero Traiguén hacia el sur surge el macizo montañoso, posee una orientación noreste-suroeste, se dispone en forma de "V" y da origen a cuencas de recepción de aguas que drenan los ríos Boldo y Boroa (Figura $N^{\circ}$ 6). En cambio, la cuenca del río Queule se desarrolla íntegramente en la vertiente marítima, donde los cerros Puralaco y Alto Pirén drenan sus afluentes principales (Pirén y Maitenco). Su longitud y ancho promedio es de 43 y 12 $\mathrm{km}$ respectivamente, el cual avanza hacia la costa abarcando los sectores de Colimán, Los Ulmos, Abanico, Las Minas, cordillera de Queule, Alto Pirén hasta los altos cerros de Puralaco (534 msnm). Dominan las series de suelo Correltué y Perquillán, los cuales se caracterizan por ser profundos, de permeabilidad lenta a moderada y bien drenados. Poseen severas limitaciones para su uso, como pendientes muy altas, alta erodabilidad, sales y clima desfavorable. Por esta razón, su aptitud se reduce a ganadero-forestal (CIREN,
2002). Por otro lado, la llanura fluviomarina se emplaza en el límite norte del área, específicamente siguiendo los cursos de agua principales que son los ríos Toltén y Queule (Figura $\mathrm{N}^{\circ}$ 6).

Una longitud de $23 \mathrm{~km}$ aproximadamente desde Fintucué hasta Ninhue. Por otro lado, la Ilanura aluvial se desarrolla entre los valles del cordón montañoso asociada a pequeñas plataformas en roca metamórfica (sector sureste y sur). Se destacan dos unidades, la primera se ubica en el valle del río Boldo, entre la vertiente occidental del cordón Colimán y la vertiente oriental del cordón los Azules y posee una longitud aproximada de $23 \mathrm{~km}$ desde el estero Soco hasta el estero Culebra. Finalmente, la segunda unidad se ubica en el valle del río Boroa entre la vertiente oriental de los cerros de Puralaco y la vertiente occidental de Mahuida y posee una longitud aproximada de $12 \mathrm{~km}$ (Figura $\mathrm{N}^{\circ}$ 6). La desembocadura del río Toltén posee características estuarinas, con una extensa 
Figura $\mathrm{N}^{\circ} 6$

Geomorfología. Río Toltén - río Queule

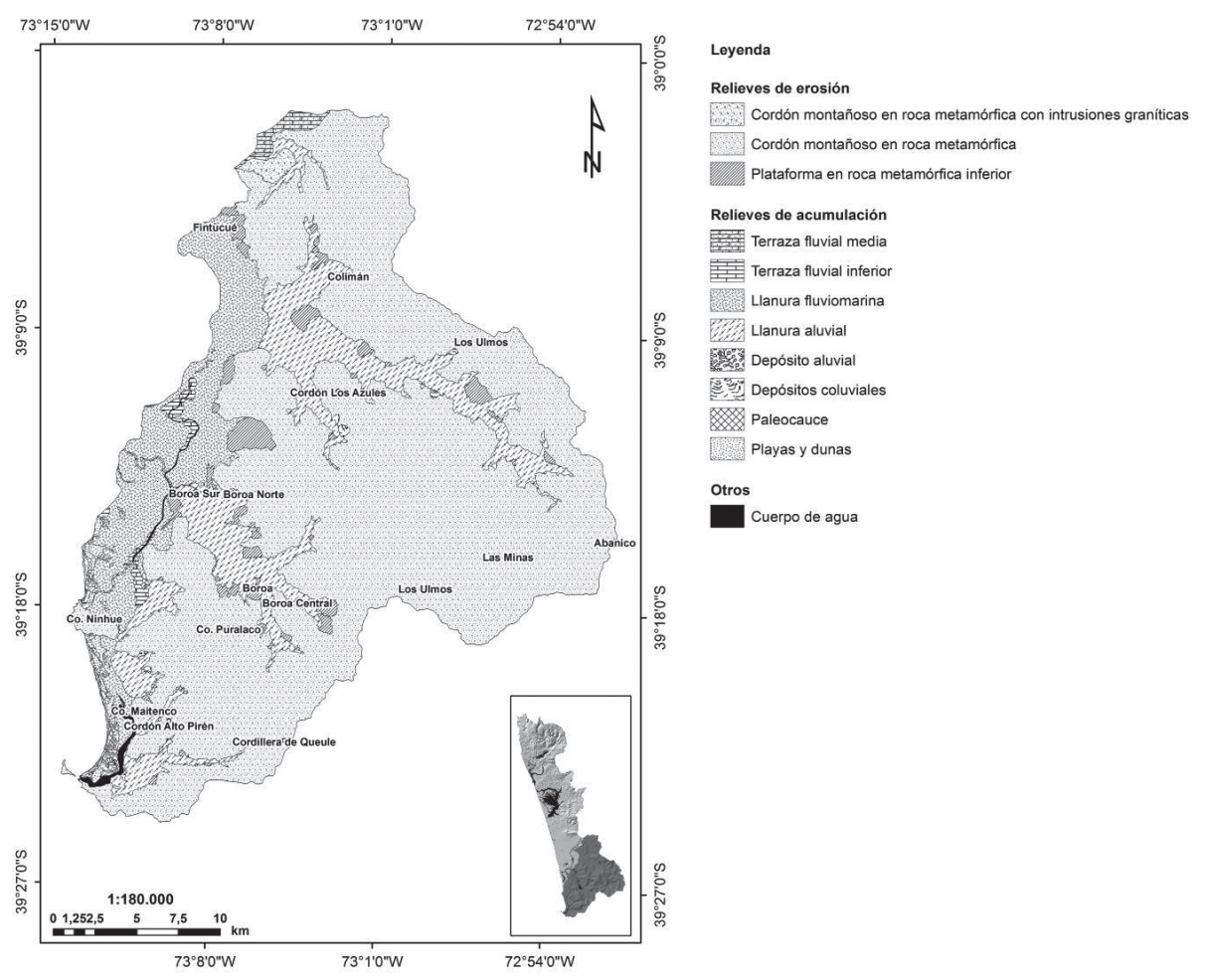

Fuente: Elaboración propia en base a proyectos FONDECYT 1030861, 1080317, 1110798.

barra, haciendo rectilínea la costa del área de estudio y obligando a ríos a correr paralelamente al litoral. Su morfogénesis está asociada principalmente a procesos tectónicos y de depositación, donde el agente marino y fluvial, ejercen una fuerte influencia sobre la depositación de material, lo que ha conformado estas Ilanuras fluviomarinas sobre las cuales se ha inscrito un relieve fluvial, el cual presenta procesos de anegamiento estacional y permanente en su extensa área.

El modelado litoral se distribuye en tres grandes campos dunarios, correspondientes a los sectores de La Barra, Nigue Norte y Nigue Sur. Las dunas presentes en los campos mencionados anteriormente están sujetos a estabilización mediante la inserción de especies introducidas como Ammophila arenaria, Lupinus arboreus y Pinus radiata (Peña-Cortés et al., 2008). La línea litoral de este sector posee una extensión aproximada de 12,5 km y un ancho promedio de $700 \mathrm{~m}$ desde el sector de La Barra hasta Queule. Predominan las dunas estabilizadas con vegetación sobre la llanura fluviomarina, donde destacan las dunas indefinidas y transversales con plantación forestal, depresiones húmedas y dunas paralelas.

En el cuadro siguiente se presenta un resumen con las unidades geomorfológicas existentes en la costa de La Araucanía y sus respectivas superficies en hectáreas y porcentaje con respecto al área total (Cuadro $\mathrm{N}^{\circ}$ 3). Es importante señalar que el detalle se ha simplificado con el objeto de agrupar en las principales unidades y procesos (Figuras $\mathrm{N}^{\circ}$ $2, \mathrm{~N}^{\circ} 3$ y $\mathrm{N}^{\circ} 6$ ). Por este motivo, el desglose del modelado litoral se agrupó en "Playas y dunas" (Cuadro N³). 
Cuadro $\mathrm{N}^{\circ} 3$

Superficie de las unidades geomorfológicas

Costa de la Región de La Araucanía

\begin{tabular}{|c|c|c|}
\hline Unidad geomorfológica & Superficie (ha) & Porcentaje del área total \\
\hline Relieves de erosión & $151.162,5$ & 72,5 \\
\hline Cordón montañoso en roca metamórfica con intrusiones graníticas & $44.003,3$ & 21,1 \\
\hline Cordón montañoso en roca metamórfica & $52.631,1$ & 25,3 \\
\hline Plataforma metamórfica & $49.606,6$ & 23,8 \\
\hline Plataforma de abrasión marina & $4.832,3$ & 2,3 \\
\hline Terraza de abrasión marina & 76,8 & 0,04 \\
\hline Cerro-isla & 12,4 & 0,01 \\
\hline Relieves de acumulación & $44.861,6$ & 21,6 \\
\hline Terraza fluvial superior & 284,3 & 0,1 \\
\hline Terraza fluvial media & $1.418,3$ & 0,7 \\
\hline Terraza fluvial inferior & $1.638,5$ & 0,8 \\
\hline Llanura fluviomarina & $26.613,5$ & 12,8 \\
\hline Llanura de inundación & 520,2 & 0,3 \\
\hline Llanura fluvial & 11,2 & 0,01 \\
\hline Llanura aluvial & $13.731,6$ & 6,6 \\
\hline Fondo de valle & 15 & 0,01 \\
\hline Depósitos coluviales & 389 & 0,2 \\
\hline paleocauce & 113,3 & 0,1 \\
\hline Aluvión & 126,7 & 0,1 \\
\hline Modelado litoral & $4.349,1$ & 2,1 \\
\hline Cordón litoral & 60,3 & 0,03 \\
\hline Dunas borderas & 456,3 & 0,2 \\
\hline Dunas paralelas & 484,4 & 0,2 \\
\hline Dunas transversales & 521,5 & 0,3 \\
\hline Dunas transversales semiestabilizadas con áreas de deflación & 183,2 & 0,1 \\
\hline Dunas transversales estabilizadas & 625,3 & 0,3 \\
\hline Dunas longitudinales & 211 & 0,1 \\
\hline Dunas activas & 51,3 & 0,02 \\
\hline Campos dunarios estabilizados & 744,2 & 0,4 \\
\hline Campos dunarios semiestabilizados & 74,4 & 0,04 \\
\hline Campos interdunarios (áreas anegadizas) & 656,4 & 0,3 \\
\hline Estrán & 280,8 & 0,1 \\
\hline Cuerpos de agua & 7.946 & 3,8 \\
\hline Total & $208.319,2$ & 100 \\
\hline
\end{tabular}

Fuente: Elaboración propia.

Destaca en la impronta del conjunto la extensa planicie fluviomarina entre el Toltén y el Queule, relieve asociado a diferentes procesos tectónicos reconociéndose en forma evidente los efectos del hundimiento provocado por el terremoto de 1960 que afecto a gran parte del sur de Chile (Cisternas et al., 2000 y 2005). 
Diferente fue la situación desde el río Toltén hacia el sur, ya que la Cordillera de la Costa permaneció desocupada hasta mediados del siglo XX, por lo que su degradación es considerablemente menor en comparación con el sector septentrional. Sin embargo, la fuerte expansión de las plantaciones forestales y la ganadería, están evidenciando los mismos efectos mencionados anteriormente para el sector norte, es decir, entre los ríos Danquil y Toltén (Mardones, 2005).

\section{La erosión hídrica en los suelos de la costa de La Araucanía}

Los resultados del estudio muestran que el estado erosivo del sector septentrional del área de estudio (río Danquil - río Imperial) es ligero a moderado (Francke et al., 2004), donde predominan los movimientos de flujo (solifluxión en terraceta y reptación) y procesos de erosión laminar y lineal (Cuadro $\mathrm{N}^{\circ} 4$ ) afectando principalmente la unidad de plataforma con 280,2 ha (Figura $N^{\circ} 7$ ).

Figura $\mathrm{N}^{\circ} 7$

Erosión lineal y laminar. Sector de Lobería

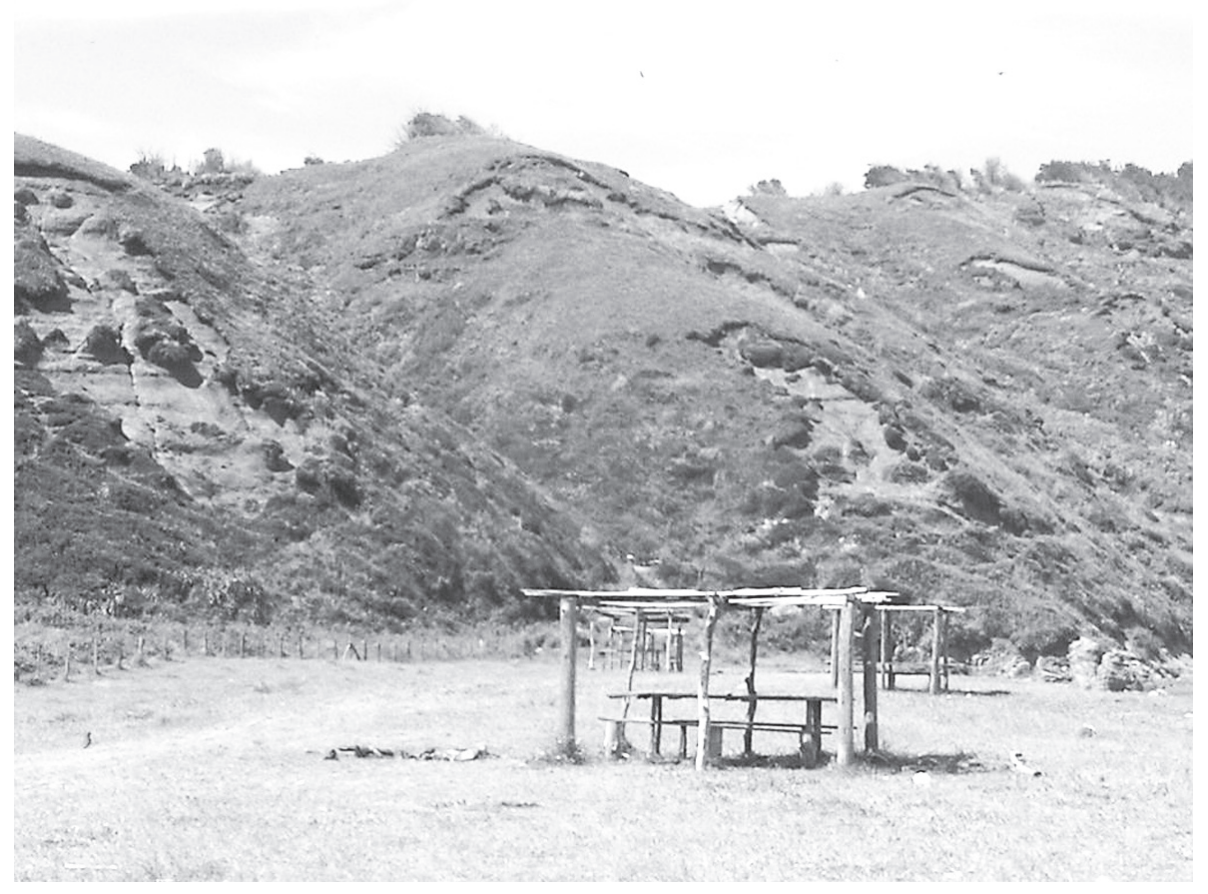

Fuente: Archivo personal de los autores.

Lo anterior se debe principalmente a que en estos relieves desarrollan una intensa actividad agrícola y forestal con nulas prácticas de conservación de suelos (destacan los sectores de Yupehue, Puyanhue y Quiripio) (Peña-Cortés et al., 2006 a y b; 2011 a y b) (ver Figura $\mathrm{N}^{\circ} 8$ ). Con respecto a la erosión hídrica lineal (ver Cuadro $N^{\circ} 5$ ), el cordón montañoso y la plataforma superior son los relieves más afectados con densidades de
9,3 y $10 \mathrm{surcos} / \mathrm{km}^{2}$ respectivamente. Esto, se debe principalmente a la tala rasa en la actividad forestal, la agresividad climática $(1.500-2.000 \mathrm{~mm})$ y a las características morfológicas y morfométricas del cordón montañoso de extensas laderas con pendientes promedio entre $6^{\circ}$ y $40^{\circ}$ (destacan los sectores de San Juan de Trovolhue y Colonia Matte y Sánchez) (Echeverría et al., 2006 y 2007; Iroumé et al., 2010). 
Figura $\mathrm{N}^{\circ} 8$

Erosión en manto. Sector de Puyanhue

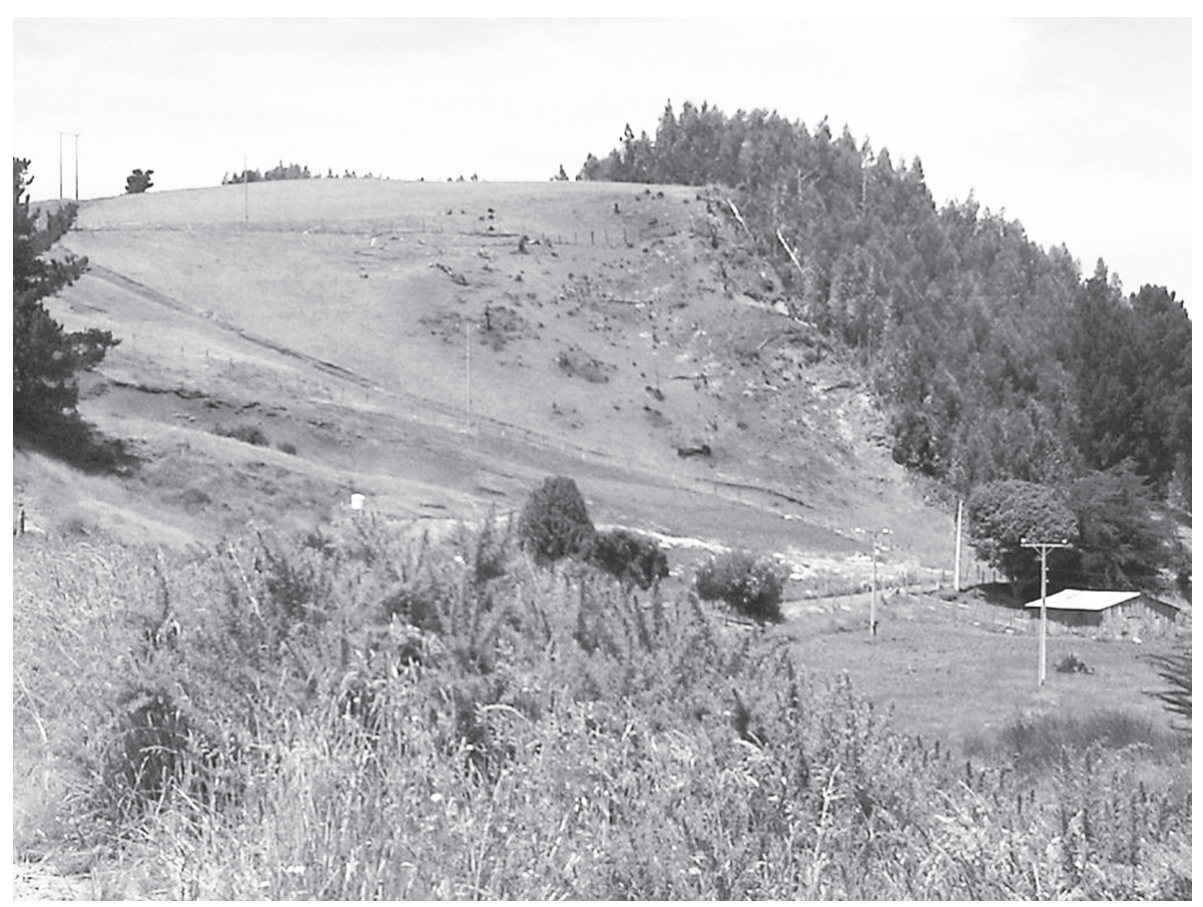

Fuente: Archivo personal de los autores.

Cuadro $\mathrm{N}^{\circ} 4$

Superficie y porcentaje de erosión laminar Sector Danquil-Imperial

\begin{tabular}{|l|r|r|}
\hline Unidad geomorfológica & \multicolumn{1}{|c|}{$\begin{array}{c}\text { Superficie unidad } \\
\text { geomorfológica (ha) }\end{array}$} & Porcentaje de erosión laminar \\
\hline Cordón montañoso & 362,7 & 1 \\
Plataforma & 280,2 & 7,7 \\
\hline
\end{tabular}

Fuente: Elaboración propia.

Cuadro $N^{\circ} 5$

Densidad de la erosión hídrica lineal según orden Sector Danquil-Imperial

\begin{tabular}{|c|c|c|c|c|c|}
\hline \multirow{2}{*}{ Unidad geomorfológica } & \multirow{2}{*}{$\begin{array}{l}\text { Números } \\
\text { de surcos }\end{array}$} & \multicolumn{3}{|c|}{ Densidad (surcos/km²) } & \multirow{2}{*}{$\begin{array}{c}\text { Total } \\
\left(\text { surcos } / \mathrm{km}^{2}\right)\end{array}$} \\
\hline & & $1^{\mathrm{er}}$ orden & $2^{\circ}$ orden & $3^{\text {er }}$ orden & \\
\hline Cordón montañoso & 2.547 & 7,6 & 1,5 & 0,2 & 9,3 \\
\hline Plataforma & 771 & 17 & 3,6 & 0,3 & 20,9 \\
\hline
\end{tabular}

Fuente: Elaboración propia. 
Con respecto al territorio comprendido entre el río Imperial y el estero Chelle, presenta un estado erosivo moderado, donde se identifican procesos de erosión laminar moderada y severa afectando principalmente a sectores emplazados sobre plataformas y cordones montañosos en roca metamórfica con 1.482 ha y 786 ha respectivamente (ver cuadro $\mathrm{N}^{\circ} 6$ ).

Por su parte, la erosión lineal afecta en su mayoría a plataformas de nivel superior, específicamente en la parte norte del lago Budi, con densidades máximas de $15 \mathrm{surcos} / \mathrm{km}$ (Cuadro $\mathrm{N}^{\circ} 7$ ). Lo anterior, se traduce en los bajos rendimientos de los cultivos, lo que explica los altos niveles de pobreza en el área. A diferencia de la parte septentrional del área de estudio, en este sector la causa principal de la erosión es la forma de ocupación del territorio donde los factores condicionantes son la baja cobertura vegetal asociada a las inadecuadas prácticas agrícolas y la alta división predial (Peña-Cortés et al., 2006a).
Finalmente, el territorio comprendido entre el río Toltén y río Queule, corresponde al sector menos degradado del área de estudio. Esto se debe principalmente al escaso desarrollo de la actividad agrícola y la baja división predial (Rebolledo, 2006; Peña-Cortes et al., 2011a). Sin embargo, en la subcuenca del río Boroa, caracterizada por su geomorfología de pendientes pronunciadas y terrenos no aptos para la actividad agrícola, se ha favorecido la expansión de terrenos forestales, los cuales en el año 2007 alcanzaron a cubrir más del $40 \%$ de su superficie (Peña-Cortés et al., 2011b).

No obstante, si persisten actividades invasivas e intensivas sobre el relieve de erosión del área de estudio, el recurso suelo se verá afectado por procesos erosivos restringiendo los usos y alterando el paisaje original que finalmente influirán en el estado ambiental de la costa de La Araucanía (Peña-Cortés et al., 2006 a y b; 2011 a y b).

Cuadro $\mathrm{N}^{\circ} 6$

Superficie y porcentaje de erosión laminar Sector Imperial-Chelle

\begin{tabular}{|l|r|r|}
\hline Unidad geomorfológica & $\begin{array}{r}\text { Superficie unidad } \\
\text { geomorfológica (ha) }\end{array}$ & Porcentaje de erosión laminar \\
\hline Cordón montañoso & 786 & 5,2 \\
Plataforma & 1.482 & 4,2 \\
\hline
\end{tabular}

Fuente: Elaboración propia.

\section{Cuadro $\mathrm{N}^{\circ} 7$}

Densidad de la erosión hidrica lineal según orden Sector Imperial-Chelle

\begin{tabular}{|l|r|r|r|r|r|}
\hline \multirow{2}{*}{ Unidad geomorfológica } & \multirow{2}{*}{$\begin{array}{c}\text { Números de } \\
\text { surcos }\end{array}$} & \multicolumn{2}{|c|}{ Densidad (surcos $\left./ \mathrm{km}^{2}\right)$} & \multirow{2}{*}{$\begin{array}{c}\text { Total } \\
\left.\text { (surcos } / \mathrm{km}^{2}\right)\end{array}$} \\
\cline { 3 - 5 } & 68 & 0,4 & 0,05 & 0,007 & 0,5 \\
Cordón montañoso & 661 & 1,5 & 0,3 & 0,06 & 1,86 \\
\hline
\end{tabular}

Fuente: Elaboración propia.

\section{Conclusiones}

Los relieves de erosión predominan en toda el área de estudio, el cual en su mayoría está constituido por cordones montañosos y plataformas en roca metamórfica. Debido a las condiciones morfológicas y morfométricas del cordón montañoso, las actividades 
agropecuarias se concentran en plataformas y zonas más cercanas a la llanura, lo que tendría relación con una antigua migración a sectores más elevados debido a que las zonas Ilanas se encuentran actualmente con severos procesos de anegamiento (humedales), lo cual ha impedido el desarrollo de la actividad agrícola. En cambio, la actividad forestal, predomina sobre la unidad de cordón montañoso y se desarrolla de forma intensiva.

Por su parte, las plataformas en roca metamórfica se observan solo en las dos primeras unidades de observación descritas (Danquil-Imperial e Imperial-Toltén), estas se caracterizan por presentar un uso agrícolaganadero y una intensa morfogénesis en las plataformas de niveles medio e inferior que se manifiestan en procesos de erosión laminar y lineal (principalmente en la costa por efecto de la acreción marina).

Por otro lado, la Ilanura fluviomarina está representada en su mayoría por humedales de alto valor ecológico, los cuales alcanzan su mayor superficie en la unidad de observación Toltén-Queule (sector sur del área de estudio). Su morfogénesis, se relaciona directamente a la depositación del material que es disgregado de las laderas por procesos de erosión.

Con respecto a las dunas litorales, el estado predominante de ellas corresponde a dunas activas, seguidas por las dunas estabilizadas con vegetación exótica (Pinus radiata).

Los procesos que más influyen en la dinámica erosiva del relieve costero son el uso de suelos no aptos para las actividades agrícolas, ganaderas y forestales, tala rasa de plantaciones forestales, inapropiadas prácticas agrícolas y la casi nula aplicación de prácticas de conservación de suelos.

Finalmente, para minimizar el deterioro del sistema por acción humana, es fundamental contar con información de base que permita a través de una adecuada planificación del territorio, tomar decisiones apropiadas con el propósito de no comprometer las futuras opciones de uso y la calidad de vida de la población.

\section{Referencias bibliográficas}

ANTON, V. Satellite Remote Sensing for Water Erosion Assessment: a Review. Catena, 2006, Nº5, p. 2-18.

APARECIDA, D. \& LUPINACCI C. Characterization of the physical elements from the Córrego Santo Antonio Basin (Río Claro/SP). Sociedade \& Natureza, Vol. 2, No 19, p. 139 151, dez. 2007.

BENGOA, J. Historia del Pueblo Mapuche (siglo XIX y XX). Santiago: Ediciones Sur, 1991.

BÖERGEL, R. Geografía de Chile, IX región de La Araucanía. Santiago de Chile: Instituto Geográfico Militar de Chile, 1986.

CENTRO DE INFORMACIÓN DE RECURSOS NATURALES (CIREN). Descripciones de suelos, materiales y símbolos. Temuco: $\mathrm{Cl}$ REN, 2002.

CISTERNAS, M.; CONTRERAS, I. y ARANEDA, A. Reconocimiento y Caracterización de la Facies Sedimentaria Depositada por el Tsunami de 1960 en el Estuario Maullín, Chile. Revista Geológica de Chile, 2000, № 27, p. 3-11.

CISTERNAS, M.; ATWATER, B.; TORREJÓN, F.; SAWAI, Y.; MACHUCA, G.; LAGOS, M.; EIPERT, A.; YOULTON, C.; SALGADO, I.; KAMATAKI, T.; SHISHIKURA, M.; RAJENDRAN, C.; MALIK, J.; RIZAL, Y. \& HUSNI, M. Predecessors of the giant 1960 Chile Earthquake. Nature, 2005, N437, p. 404-407.

DONOSO, C. y LARA, A. Utilización de los bosques nativos en Chile: pasado, presente y futuro. En: ARMESTO, J.; C VILLAGRÁN y KALIN, M. (editores). Ecología de los bosques nativos de Chile. Santiago de Chile: Editorial Universitaria, 1997, p. 363-387.

ECHEVERRÍA, C.; COOMES, D.; SALAS, J.; REY-BENAYAS, J.M.; LARA, A. \& NEWTON, A. Rapid deforestation and fragmentation of Chilean Temperate Forests. Biological Conservation, 2006, N 130, p. 481-494.

ECHEVERríA, C.; HUBER, A. y TABERLET, F. Estudio Comparativo de los Componentes 
del Balance Hídrico en un Bosque Nativo y una Pradera en el Sur de Chile. Bosque, 2007, Vol. 3, No 28, p. 271-280.

ELIZALDE, R. La Sobrevivencia de Chile: La Conservación de sus Recursos Naturales Renovables. Santiago de Chile: Ministerio de Agricultura, 1970.

ENDLICHER, W. Geokologische Untersuchungen zur Landschaftsdegradation im Küstenbergland von Concepción (Chile). Freiburg: Geowissenshaftlichen Fakultat der Universitat Freiburg, 1985.

ENDLICHER, W. El Problema de la Erosión del Suelo en la Cordillera de la Costa de la Octava Región. Revista de Geografía Norte Grande, 1988, № 15, p. 11-27.

FOOD AND AGRICULTURE ORGANIZATION (FAO). Guidelines for Soil Description. Food and Agriculture Organization of United Nations. Rome: FAO, 2006.

FRANCKE, S.; VARGAS, R.; WILLIAMS, E.; PINTO, M. y YOMA, R. Recuperación de Suelos Degradados en el Marco del DL-701 de Fomento Forestal (Período 2000-2003). Santiago de Chile: Ministerio de Agricultura, 2004.

GUERRERO, R. Evaluación de la Erosión Hídrica en el Borde Costero de la IX Región de La Araucanía, en el Interfluvio Río Imperial y el Estero Chelle. Tesis de Grado para Optar al Título de Biólogo en Gestión de Recursos Naturales. Temuco: Universidad Católica de Temuco, 2003.

HAUENSTEIN, E.; PEÑA-CORTÉS, F.; BERTRÁN, C.; TAPIA, J. y SCHLATTER, R. Comparación Florística y Estado Trófico Basado en Plantas Indicadoras de Lagunas Costeras de la Región de La Araucanía, Chile. Ecología Austral, 2008, N 18, p. 43-53.

HONORATO, R.; BARRALES, L.; PEÑA, I. y BARRERA, F. Evaluación del Modelo U.S.L.E en la Estimación de la Erosión en Seis Localidades entre La IV y IX Región de Chile. Ciencia e Investigación Agraria, 2001, № 28, p. 7-14.
INSTITUTO GEOGRÁFICO MILITAR (IGM). Geografía de Chile. IX Región de La Araucanía. Santiago de Chile: IGM, 1986.

IROUMÉ, A.; PALACIOS, H.; BATHURST, J. y HUBER, A. Escorrentías y Caudales Máximos luego de la Cosecha a Tala Rasa y del Establecimiento de una Nueva Plantación en una Cuenca Experimental del Sur de Chile. Bosque, 2010, Vol. 2, №31, p. 117-128.

IROUMÉ, A.; GAYOSO, J. Y HERNÁNDEZ, M. Caracterización de Cárcavas en las Regiones VIII y IX de Chile. Bosque, 1994, Nº 15 , p. 65-75.

IREN-CORFO. Fragilidad de los Ecosistemas Naturales de Chile. Santiago de Chile: IREN-CORFO, 1979.

LLONA, M.; ARAYA-VERGARA, J. y VERA, W. Relación entre morfogénesis y pedogénesis en la cuenca del río Clarillo, Región Metropolitana de Santiago, Chile. Revista de Geografía Norte Grande, 2007, №37, p. 47-61.

LUEBERT, F. y PLISCOFF, P. Bioclimas de la Cordillera de la Costa del centro-sur de Chile. En: SMITH-RAMÍREZ, C.; ARMESTO, J. y VALDOVINOS, C. Historia, Biodiversidad y Ecología de los Bosques Costeros de Chile. Santiago de Chile: Editorial Universitaria, 2005, p. 60-73.

LUIS, J. Estudio del Relieve para la Gestión Ambiental, con el Uso de Sistemas de Información Geográficos (SIG). Revista Internacional de Ciencias de la Tierra, 2004. Disponible en internet:

http://www.mappinginteractivo.com/plantilla-ante.asp?id_articulo=816. 2004.

MARDONES, M. La cordillera de la Costa: Caracterización Físico-Ambiental y Regiones Morfoestructurales. En: SMITH-RAMÍREZ C, ARMESTO J y VALDOVINOS, C. Historia, Biodiversidad y Ecología de los Bosques Costeros de Chile. Santiago de Chile: Editorial Universitaria, 2005, p. 39-59.

MEYBECK, M. \& VOROSMARTY, CJ. The Integrity of River and Drainage Basin Systems: Challenges from Environmental Change. In: KABAT, P. (editor). Vegetation, Water, Humans and the Climate: A New Perspective on an In- 
teractive System (Part D). NY: Springer-Verlag, 2004, p. 297-479.

MODENESI-GAUTTIERI M, MOTTA MC, TAKASHI S, TAIOLI F y SHIMADA H. Deep Weathering and Landscape Evolution in a Tropical Plateau. Catena, 2011, $N^{\circ}$ 85, p. 221-230.

MORGAN, R. Erosión y conservación de suelos. Madrid: Ediciones Mundi-Prensa, 1997.

OYARZÚN, C. Estimación de los Procesos de Erosión Hídrica en un Ambiente Montañoso de la Cuenca del Río Bío-Bío, Región del Bío-Bío, Chile. Concepción: Tesis Doctorado en Ciencias Ambientales, Universidad de Concepción, 1993.

PASKOFF, R.; MANRÍQUEZ, H.; CUITIÑO, L. y PETIOT, R. Características, Origen y Cronología de los Cordones Dunares de la playa de Santo Domingo, Región de Valparaíso, Chile. Revista geológica de Chile, 2000, No27, p. 121-131.

PEÑA-CORTÉS, F. Geomorfología de la Ribera Norte del Río Biobío en su Curso Inferior. Limitaciones y Potencialidades del área. Revista de Geografía Norte Grande, 1995, Nº 22 , p. 27-33.

PEÑA-CORTÉS, F. Bases para la Planificación Territorial del Curso Inferior del Río Itata. Análisis Integrado de los Sistemas Geográficos. Concepción: Tesis Doctorado en Ciencias Ambientales, Universidad de Concepción, 1999.

PEÑA-CORTÉS, F. y MARDONES, M. Geomorfología del Curso Inferior del Río Itata. VIII Región del Bíobío. Revista Geográfica de Chile Terra Australis, 1999, N 44, p. 31-44.

PEÑA-CORTÉS， F.; BERTRÁN，C.; SCHLATTER, R.; HAUENSTEIN, E.; DURÁN, T. y TAPIA, J. Proyecto FONDECYT 1030861 Análisis Integrado del Borde Costero de la IX Región. Propuestas y Criterios para la Planificación Ecológica de sus Humedales. Concepción: Informe de Avance, 2005.
PEÑA-CORTÉS, F.; GUTIÉRREZ, P.; REBOLLEDO, G.; ESCALONA, M.; HAUENSTEIN, E.; BERTRÁN, C.; SCHLATTER, R. y TAPIA, J. Determinación del Nivel de Antropización de Humedales como Criterio para la Planificación Ecológica de la Cuenca del Lago Budi, IX Región de La Araucanía, Chile. Revista de Geografía Norte Grande, 2006a, N³6, p. 75-91.

PEÑA-CORTÉS, F.; REBOLLEDO, G.; HERMOSILLA, K.; HAUENSTEIN, E.; BERTRÁN, C.; SCHLATTER, R. y TAPIA, J. Dinámica del Paisaje para el Periodo 1980-2004 en la Cuenca Costera del Lago Budi, Chile. Consideraciones para la Conservación de sus Humedales. Ecología Austral, 2006b, № 16, p. 183-196.

PEÑA-CORTÉS, F.; AILIO, C.; GUTIÉRREZ, P.; ESCALONA-ULLOA, M.; REBOLLEDO, G.; PINCHEIRA-ULBRICH, J.; ROZAS, D. y HAUENSTEIN, E. Morfología y Dinámica Dunaria en el Borde Costero de la Región de La Araucanía en Chile. Antecedentes para la Conservación y Gestión Territorial. Revista de Geografía Norte Grande, 2008, № 41, p. 63-80.

PEÑA-CORTÉS, F.; ESCALONA-ULLOA, M.; REBOLLEDO, G. Y PINCHEIRA-ULBRICH, J. Cambios de Uso de Suelo en las Cuencas Costeras de La Araucanía entre los Años 1994 y 2007. Anales de la Sociedad Chilena de Ciencias Geográficas, 2010, p. 6.

PEÑA-CORTÉS, F.; PINCHEIRA-ULBRICH, J.; BERTRÁN, C.; TAPIA, J.; HAUENSTEIN, E.; FERNÁNDEZ, E. y ROZAS, D. A Study of the Geographic Distribution of Swamp Forest in the Coastal Zone of the Araucanía Region, Chile. Applied Geography, 2011a, N 31, p. 545-555.

PEÑA-CORTÉS, F.; PINCHEIRA-ULBRICH, J.; ESCALONA-ULLOA, M. \& REBOLLEDO, G. Cambio de Uso del Suelo en los Geosistemas de la Cuenca Costera del Río Boroa (Chile) entre 1994 y 2004. 2011b, N 43, p. 35-45.

REBOlledO, G. Dinámica del Paisaje: Patrones y Procesos para la Planificación Ecológica del Borde Costero de La Araucanía. Tesis presentada para optar al grado de Magíster en 
Ciencias. Puerto Montt: Universidad de Los Lagos, 2006.

SUVIRES. G. y LUNA, P. Unidades Geomorfológicas Ambientales del Sur del Oasis del Tulum, Andes Centrales de Argentina. Multequina, 2008, № 17, p. 109-128.

TRICART, J. Príncipes et Methodes de la Geomorphologie. Paris: Masson et Cie editeurs, 1985.
TORREJÓN, F. y CISTERNAS, M. Alteraciones del Paisaje Ecológico Araucano por la Asimilación Mapuche de la Agroganadería Hispano-Mediterránea (Siglos XVI y XVII). Revista Chilena de Historia Natural, 2002, Nº 75, p. 729-736.

VITOUSEK, P.; MOONEY, H.; LUBCHENCO, J. y MELILLO, J. Human Domination of Earth's Ecosystems. Science, 1997, № 277, p. 494-499. 